\title{
Utilização de Método Indireto para Predição da Composição Química Corporal de Zebuínos ${ }^{1}$
}

\author{
André Mendes Jorge ${ }^{2}$, Carlos Augusto de Alencar Fontes ${ }^{3}$, Mário Fonseca Paulino 4 , \\ Paulo Gomes Júnior ${ }^{5}$
}

\begin{abstract}
RESUMO - O objetivo deste trabalho foi desenvolver equações de predição da composição química corporal de zebuínos, por intermédio da análise química de amostra de seção representativa da carcaça. Utilizaram-se sessenta e três animais não-castrados das raças Gir, Guzerá, Mocho de Tabapuã e Nelore. Os conteúdos corporais de proteína, gordura e macroelementos minerais (cálcio, fósforo,

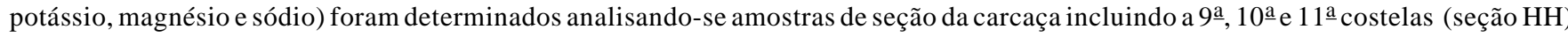
e dos demais tecidos corporais. Os teores de proteína, gordura, energia e macroelementos minerais da secção HH, com exceção para o magnésio, mostraram-se altamente correlacionados com a composição química corporal. As equações de predição baseadas na composição química da secção HH mostraram-se confiáveis para estudos comparativos da composição corporal de zebuínos.
\end{abstract}

Palavras-chave: bovinos, composição corporal, equações de predição

\section{Use of Indirect Method to Predict Chemical Body Composition in Zebu Cattle}

\begin{abstract}
The objective of this study was to develop equations to predict chemical body composition from zebu cattle, based on chemical composition from carcass representative section. Sixty-three young bulls from Gyr, Guzera, Nellore and Mocho de Tabapuã breeds were used. Body content of protein, fat and minerals were determined on samples from the carcass section that included the $9^{\text {th }}$, $10^{\text {th }}$ and $11^{\text {th }}$ rib joint (HH joint), and from the remaining body tissues. Protein, fat, energy and ash contents from the HH joint, except for magnesium, were closely related to protein, fat, energy and ash contents in the body. Prediction equations based on chemical composition from $\mathrm{HH}$ joint showed to be reliable for comparative studies of body composition of zebu cattle.
\end{abstract}

Key Words: cattle, body composition, prediction equations

\section{Introdução}

HANKINS e HOWE (1946) utilizaram secção da carcaça para a predição da composição química da carcaça de bovinos e observaram correlações significativas de 0,83 ; 0,91 ; e 0,53 entre os teores de proteína, gordura e cinzas da seção $\mathrm{HH}$ e àqueles obtidos por análise química da carcaça. No exterior, as equações propostas pelos referidos autores têm sido constantemente validadas (COLE et al., 1962; POWELL e HUFFMAN, 1968; e LANNA, 1995) e, recentemente, NOUR e THONNEY (1994), trabalhando com bovinos Angus e Holandês, relataram que a composição da seção HH pode ser utilizada, com precisão, na predição da composição da carcaça, efetuando-se pequenos ajustes para o tipo racial.

O desenvolvimento de métodos indiretos para determinação da composição química, aplicáveis às condições brasileiras, abre perspectivas de ampliação dos estudos da composição química corporal e da carcaça (MORAIS et al., 1993).

As informações disponíveis no Brasil sobre a composição química corporal, de diferentes raças e em diversas maturidades fisiológicas, são ainda limitadas, em virtude de sua determinação ser trabalhosa e de alto custo.

PERON et al. (1993), trabalhando com bovinos de cinco grupos genéticos, desenvolveram equações de predição da composição química corporal e da carcaça a partir de seções desta, incluindo a seção da 9a a 11 costelas (seção HH) e encontraram correlações de 0,$93 ; 0,99$; e 0,92 , respectivamente, entre os teores de proteína, gordura e cinza no corpo vazio e a concentração dos mesmos na seção HH. Os mes-

\footnotetext{
1 Trabalho realizado em colaboração com a EPAMIG/FAPEMIG.

2 Professor Assistente Doutor do D.P.E.A./FMVZ/UNESP - Caixa Postal 560 - Botucatu - SP. 18618-000. Pesquisador do CNPq E.mail: jorgeam@fca.unesp.br

3 Professor Titular UENF, Campos-RJ. Pesquisador do CNPq.

${ }^{4}$ Professor do DZO/UFV, Viçosa-MG.

5 Mestre em Zootecnia, DZO/UFV.
} 
mos autores concluíram que as equações de predição da composição química corporal, com os mais elevados coeficientes de determinação, foram obtidos com base na composição química da seção $\mathrm{HH}$.

O peso do conteúdo do trato gastrintestinal (TGI) exerce influência direta sobre o ganho de peso vivo (BERG e BUTERFIELD, 1976; FOX et al., 1976; FONTES, 1995). Desse modo, quando se deseja expressar mais adequadamente o desempenho animal nos experimentos de alimentação e sistemas de produção, pode-se utilizar o peso corporal vazio (PCVZ). Entretanto, além do custo e da mão-de-obra, o PCVZ só pode ser determinado, após o abate, deduzindo-se do PV o peso do conteúdo do TGI ou somando-se os pesos de todos os componentes do corpo do animal, tornando-se inviável nos casos de avaliações seguidas em um mesmo animal.

Uma alternativa mais prática seria estimar o PCVZ a partir do PV. Com este objetivo, muitas pesquisas foram conduzidas e permitiram concluir que, a partir do PV, pode-se estimar o PCVZ com bastante precisão (AGRICULTURAL RESEARCH COUNCIL ARC, 1980; WRIGHT e RUSSEL, 1984) por intermédio da equação: $\mathrm{PCVZ}=-43,1+0,93 * \mathrm{PV}$, com $\mathrm{r}^{2}=0,98$.

FONTES (1995), em uma análise conjunta de dados obtidos em diferentes experimentos, referentes a 281 animais das raças zebuínas, mestiços de raças européias leiterias e zebuínas e mestiços de raças européias de corte e zebuínas, com pesos variando entre 200 e $550 \mathrm{~kg}$, obteve as seguintes equações de predição: $\mathrm{PCVZ}=-19,6138+0,92585 * \mathrm{PV} \quad \mathrm{r}^{2}=0,97$, para zebuínos e PCVZ $=-34,3368+0,92585 * \mathrm{PV}$ $\mathrm{r}^{2}=0,97$ para mestiços europeu-zebu.

CASTILLO ESTRADA (1996), ao abater animais Nelore, $F_{1}$ Nelore-Angus, $F_{1}$ Nelore-Holandês e $F_{1}$ Nelore-Normando, com pesos vivos entre 350 e $550 \mathrm{~kg}$, obteve a equação: $\mathrm{PCVZ}=-50,6829+0,9741 * \mathrm{PV}$, com $r^{2}=97,0 \%$.

Objetivou-se, neste estudo, obter equações de predição da composição corporal, a partir da composição química de seção da carcaça, aplicáveis a zebuínos.

\section{Material e Métodos}

O presente estudo foi realizado na Universidade Federal de Viçosa. Foram utilizados dados de 63 bovinos machos não-castrados, sendo 16 Gir (GIR), 16 Guzerá (GUZ), 15 Nelore (NEL) e 16 Mocho Tabapuã (TAB), com idade média de 24 meses e pesos médios iniciais de 357,6 $\pm 32,95,362,0 \pm 28,95$, $376,4 \pm 28,56$ e $368,6 \pm 25,83 \mathrm{~kg}$, respectivamente, pro- venientes da EPAMIG, Minas Gerais. Esses animais foram confinados em baias individuais concretadas com área de $30 \mathrm{~m}^{2}$, oito das quais eram cobertas com telhas de fibro-cimento. As baias dispunham de comedouro e bebedouro de cimento.

Os animais de cada raça foram distribuídos em cinco grupos, cada um designado, aleatoriamente, para um dos tratamentos (categorias): abate inicial ou referência $(A B)$; alimentação restrita $(A R)$; e alimentação ad libitum até o abate, a um peso vivo de 405,450 e $500 \mathrm{~kg}$, equivalente a 90, 100 e $110 \%$ do peso estimado à maturidade das fêmeas da raça (categoria 1, 2 e 3), respectivamente. No tratamento $\mathrm{AB}$, foram alocados quatro animais das raças Gir, Guzerá e Mocho-Tabapuã e três da raça Nelore. Nos demais tratamentos foram alocados três animais de cada raça.

Os animais das categorias 1, 2 e 3 receberam, durante o período experimental, uma ração balanceada ad libitum, formulada segundo as normas do NATIONAL RESEARCH COUNCIL - NRC (1984) de modo a permitir ganho diário de $1,1 \mathrm{~kg}$, atendendo, ao mesmo tempo, às exigências de proteína degradável no rúmen (PDR) e proteína não-degradável no rúmen (PNDR), segundo o ARC (1980). Procurou-se sempre manter a proporção concentrado: volumoso próxima de $1: 1$, na matéria seca (MS). A ração foi fornecida aos animais da categoria AR em quantidades limitadas, de forma a ingerirem quantidades de energia e proteína $15 \%$ acima das exigências de mantença.

A composição percentual da ração experimental é apresentada na Tabela 1 e os teores de matéria seca

Tabela 1 - Composição da ração experimental (\% MS) Table 1 - Composition of experimental diet (\%DM)

\begin{tabular}{lc}
\hline $\begin{array}{l}\text { Ingrediente } \\
\text { Ingredient }\end{array}$ & $\begin{array}{c}\text { Ração } \\
\text { Diet }\end{array}$ \\
\hline $\begin{array}{l}\text { Feno de capim-braquiária } \\
\text { Signal grass hay }\end{array}$ & 50,34 \\
$\begin{array}{l}\text { Milho grão triturado } \\
\text { Ground corn }\end{array}$ & 38,00 \\
$\begin{array}{l}\text { Farelo de soja } \\
\text { Soybean meal }\end{array}$ & 10,00 \\
$\begin{array}{l}\text { Uréia } \\
\text { Urea }\end{array}$ & 0,77 \\
$\begin{array}{l}\text { Mistura mineral } \\
\text { Premix mineral }^{1}\end{array}$ & 0,89 \\
\hline
\end{tabular}

1 Fosfato bicálcico, 79,16\%; calcário calcítico, 7,9\%; cloreto de sódio, $9,63 \%$; sulfato de zinco, $1,00 \%$; sulfato de cobre, $0,25 \%$; iodato de potássio, $0,03 \%$; sulfato de cobalto, $0,03 \%$.

1 Dicalcium phosphate, $79.16 \%$; limestone, $7.9 \%$; sodium cloride, 9.63\%; zinc sulfate, $1.00 \%$;cupper sulfate, $0.25 \%$, potassium iodine, $0.03 \%$; cobalt sulfate, $0.03 \%$. 
1864 Rev. bras. zootec.

(MS), proteína bruta (PB), energia metabolizável (EM) e macroelementos minerais dos ingredientes e da ração, na Tabela 2 .

O período experimental não teve duração préfixada, uma vez que os animais foram abatidos assim que atingiram os pesos pré-estabelecidos de 405, 450 ou $500 \mathrm{~kg}$, correspondentes as tratamentos (categorias) 1,2 e 3 , respectivamente. Ao ser abatido um animal da categoria 2, era abatido um animal da categoria AR.

Antes do período de adaptação, os animais foram pesados, após jejum de 16 horas, identificados com brincos numerados e submetidos ao controle de endo e ectoparasitas e receberam 2.000 .000 UI de vitamina A injetável.

Os animais foram pesados a cada 28 dias e, à medida que um animal se aproximava do peso de abate preestabelecido, era pesado a intervalos menores, de forma a ser abatido com o peso previsto.

Ao atingir o peso de abate, $o$ animal foi submetido a um período de 16 horas de jejum, com acesso à água. O abate ocrria após pesagem do animal, por concussão cerebral e posterior seção da veia jugular. De cada animal abatido, pesaram-se e coletaram-se amostras de sangue, rúmen-retículo, omaso, abomaso, intestinos delgado e grosso, mesentério, carne industrial, gordura interna, fígado, coração, rins, baço, pulmão, língua, couro, cauda, esôfago, traquéia e aparelho reprodutor. Para um animal de cada raça, foram pesadas, dissecadas e retiradas amostras de uma cabeça e um pé.

A carcaça era dividida em duas metades, com o auxílio de uma serra elétrica, e estas pesadas individualmente. Em seguida, as duas metades da carcaça foram levadas à câmara fria, onde permaneceram por aproximadamente 18 horas, a $-5^{\circ} \mathrm{C}$. Decorrido este tempo, utilizando-se a metade esquerda da carcaça, retirou-se a secção transversal, incluindo a $9 \stackrel{\mathrm{a}}{ }, 10^{\mathrm{a}} \mathrm{e}$ e $11^{\mathrm{a}}$ costelas, da qual se destacou a secção segundo HANKINS e HOWE (1946), secção HH.

As amostras de sangue, carne, gordura, couro, osso e cauda e amostras compostas de vísceras e órgãos foram processadas conforme descrito por PAULINO (1996), que determinou as exigências nutricionais dos animais utilizados neste trabalho.

As análises de nitrogênio total foram feitas em aparelho semimicro Kjeldahl; as de extrato etéreo, em aparelho Goldfish; e as de cinza, em mufla elétrica a $600^{\circ} \mathrm{C}$. Na determinação dos macroelementos minerais, foi preparada solução mineral pela via úmida. $\mathrm{O}$ fósforo foi determinado em espectrofotômetro (colorímetro), segundo o método adaptado por BRAGA e DEFILIPO (1979). O cálcio e o magnésio foram determinados em espectrofotômetro de absorção atômica (aparelho Varian, modelo AA-175) e o sódio e o potássio, em espectrofotômetro de chama (Corning, modelo 400). As análises foram realizadas conforme metodologia descrita por SILVA (1990).

Nas secções retiradas da carcaça (secção HH), determinaram-se as proporções dos componentes físicos (músculo, tecido adiposo e ossos) e a composição química dos mesmos (proteína, extrato etéreo e macroelementos minerais).

As proporções de músculo, tecido adiposo e ossos da carcaça foram determinadas com base nas proporções desses componentes na secção $\mathrm{HH}$, por

Tabela 2 - Composição química do feno, concentrado e da ração experimental (\% da MS)

Table 2 - Chemical composition of the hay, concentrate and experimental diet (\% DM)

\begin{tabular}{lcccccccc}
\hline & \multicolumn{7}{c}{ Teores na matéria seca } \\
Dry matter basis
\end{tabular}

1 Análises realizadas no Laboratório de Nutrição Animal do Departamento de Zootecnia da UFV.

2 Determinado por meio de ensaio de digestibilidade, considerando EM = ED x 0,82 (PAULINO, 1996).

3 EM = Energia metabolizável.

1 Analyses carried out at the Animal Nutrition Laboratory, Department of Animal Science of Universidade Federal de Viçosa.

2 Determined from digestibility trial, considering ME = DE x.82 (PAULINO, 1996).

${ }^{3} \mathrm{ME}=$ Metabolizable energy. 
meio das equações abaixo, desenvolvidas por HANKINS e HOWE (1946):

$\begin{array}{ll}\text { Músculo } & \mathrm{Y}=16,08+0,80 * \mathrm{X} \\ \text { Tecido adiposo } & \mathrm{Y}=3,54+0,80 * \mathrm{X} \\ \text { Ossos } & \mathrm{Y}=5,52+0,57 * \mathrm{X}\end{array}$

em que Xé a porcentagem do componente na secção HH.

A composição química corporal foi determinada, considerando-se o peso e a composição de cada parte do corpo (sangue, couro, cauda, vísceras e órgãos) e dos componentes isolados (músculos, tecido adiposo e osso) da secção HH, da cabeça e dos pés.

Os conteúdos corporais de água, proteína, gordura, energia e cinzas foram obtidos conforme descrito por PAULINO (1996), que, igualmente, utilizou os animais do presente estudo.

O peso corporal vazio dos animais-referência (AB) foi determinado somando-se os pesos de carcaça, sangue, cabeça, pés, couro, cauda, vísceras e órgãos. Relações específicas entre o peso corporal vazio (PCVZ) e o peso vivo (PV) foram determinadas para animais de cada raça. $\mathrm{O}$ valor obtido para cada raça foi utilizado para se estimar o PCVZ inicial dos animais experimentais das categorias remanescentes (AR, 1, 2 e 3). O PCVZ final destes animais foi determinado de modo semelhante ao obtido pelos animais-referência, por ocasião do abate.

As análises estatísticas foram feitas utilizando-se o programa LSMLMW, versão PC-1, segundo HARVEY (1987).

$O$ efeito de regressão, pela raça e geral, do PCVZ inicial para as características estudadas foi pesquisado em análises preliminares, sendo excluído do modelo por não se mostrar significativo.

Equações de predição da composição química corporal (proteína, gordura e macroelementos minerais) foram ajustadas em função da composição química da seção HH, utilizando-se o modelo geral:

$$
Y_{i j}=m+b_{1 i} X_{i j}+e_{i j}
$$

em que $Y_{i j}$ é porcentagem de proteína, gordura e cinzas e conteúdo de energia (Mcal) no corpo vazio, do animal $j$, da raça $i ; \mu$, efeito da média (intercepto); $\mathrm{b}_{1 \mathrm{i}}$, coeficiente de regressão das porcentagens de proteína, gordura e cinzas e do conteúdo de energia (Mcal) no corpo vazio, em função das porcentagens de proteína, gordura e cinzas e conteúdo de energia (Mcal) na secção $\mathrm{HH}$, para a raça $\mathrm{i}$, em que $\mathrm{i}=1$, (GIR), 2 (GUZ), 3 (NEL) e 4 (TAB); $\mathrm{X}_{\mathrm{ij}}$, porcentagem de proteína, gordura e cinzas e conteúdo de energia (Mcal), na secção HH, do animal j da raça $\mathrm{i}$; e $\mathrm{e}_{\mathrm{ij}}$, erro aleatório, pressuposto normalmente distribuído, com média zero e variância $\sigma^{2}$.
De modo semelhante, foi ajustada equação de predição do peso corporal vazio (PCVZ), em função do peso vivo (PV) em jejum.

Na equação de predição do PCVZ, em função do $\mathrm{PV}$, adotou-se o modelo a seguir:

$$
Y_{i j}=\mu+b_{1 i} X_{i j}+e_{i j} \text {, }
$$

em que $Y_{i j}$, pesos de corpo vazio, do animal $j$, da raça $i$; $\mu$, efeito da média (intercepto); $b_{1 i}$, coeficiente de regressão linear do peso de corpo vazio, em função do peso vivo, para a raça $i$, em que $i=1$ (GIR), 2 (GUZ), 3 (NEL) e 4 (TAB); $X_{i j}$, peso vivo do animal $j$, da raça $i$; e $\mathrm{e}_{\mathrm{ij}}$, erro aleatório, pressuposto normalmente distribuído, com média zero e variância $\sigma^{2}$.

\section{Resultados e Discussão}

Não se observou diferença $(\mathrm{P}>0,05)$ entre raças quanto aos parâmetros analisados.

Os parâmetros das equações de predição das porcentagens de proteína e gordura, do conteúdo de energia e das porcentagens dos macroelementos minerais, no corpo vazio, em função das porcentagens dos respectivos componentes na seção "Hankins e Howe" - seção HH, são apresentados nas Tabelas 3 e 4 , respectivamente.

De modo geral, verificaram-se altos coeficientes de determinação para equações de predição dos componentes químicos do corpo vazio, em função do teores na seção HH. Apenas para magnésio, embora altamente significativo $(\mathrm{P}<0,01)$, o valor obtido foi mais baixo, mostrando bom ajustamento das equações aos dados experimentais. Valores semelhantes foram encontrados por PERON et al. (1993), que utilizaram a mesma metodologia,. De maneira semelhante, ALHASSAN et al. (1975) encontraram correlações de 0,96 e 0,94 , respectivamente, entre os teores de gordura da seção $\mathrm{HH}$ e a porcentagem de gordura no corpo vazio de bovinos das raças Angus e Hereford. Esses autores relataram que não foram obtidas equações capazes de estimar com precisão a porcentagem de macroelementos minerais. Deve-se ressaltar que a secção HH foi usada como amostra representativa da carcaça no presente estudo, que incluiu também amostras de todos os demais tecidos corporais. Isto explicaria, em boa parte, a associação mais estreita entre o conteúdo de macroelementos minerais da carcaça e do corpo vazio aqui obtidos.

As equações foram ajustadas para as quatro raças, das categorias de ganho (1, 2 e 3 ), em conjunto, devido ao pequeno número de animais em cada raça e ao fato de as análises anteriores terem revelado 
1866 Rev. bras. zootec.

Tabela 3 - Parâmetros das equações de regressão (PER) das porcentagens de proteína e gordura e do conteúdo corporal de energia no corpo vazio, em função das porcentagens de proteína e gordura e do conteúdo de energia na secção HANKINS e HOWE (secção $H H$ ), determinadas por análise química

Table 3 - Parameters of regression equations (PRE) of empty body content of protein (\%), fat (\%) and energy (Mcal), in function of protein and fat contents (\%) and empty body content of energy (Mcal) in "Hankins \& Howe" section (HH section) determined by chemical analysis

\begin{tabular}{|c|c|c|c|}
\hline \multirow[t]{2}{*}{$\begin{array}{l}\text { Nutriente } \\
\text { Nutrient }\end{array}$} & \multicolumn{3}{|c|}{$\begin{array}{l}\text { PER } \\
P R E\end{array}$} \\
\hline & $\begin{array}{l}\text { Intercepto } \\
\text { Intercept }\end{array}$ & $\begin{array}{c}\text { Coeficiente de regressão }(\beta) \\
\text { Coefficient of regression }(\beta)\end{array}$ & $\mathrm{R}^{2}$ \\
\hline $\begin{array}{l}\text { \% proteína corporal/PB na secção } \mathrm{HH} \\
\text { Body protein } \% / C P \text { in } H H \text { section }\end{array}$ & 4,857738 & 0,751038 & $0,84^{* *}$ \\
\hline $\begin{array}{l}\text { \% gordura corporal/GO na secção } \mathrm{HH} \\
\text { Body fat \%/Fat in HH section }\end{array}$ & 2,758112 & 0,799456 & $0,88^{* *}$ \\
\hline $\begin{array}{l}\text { Mcal energia corporal/Mcal na secção HH } \\
\text { Body energy Mcal/Mcal in HH section }\end{array}$ & 0,474425 & 0,804705 & $0,88^{* *}$ \\
\hline
\end{tabular}

${ }^{* *}$ Significativo $(\mathrm{P}<0,01)$ (Significant $(P<.01)$.

Tabela 4 - Parâmetros das equações de regressão (PER) das porcentagens de cálcio, fósforo, potássio, magnésio e sódio no corpo vazio, em função das porcentagens de cálcio, fósforo, potássio, magnésio e sódio na secção "HANKINS e HOWE" (secção HH), determinadas por análise química

Table 4 - Parameters of regression equations (PRE) of empty body contents (\%) of calcium, phosphorus, potassium, magnesium and sodium, in function of calcium, phosphorus, potassium, magnesium and sodium content (\%) in "Hankins \& Howe" section (HH section) determined by chemical analysis

\begin{tabular}{lccc}
\hline Nutriente & \multicolumn{3}{c}{ PER } \\
Nutrient & PRE & \multicolumn{2}{c}{$\mathrm{R}^{2}$} \\
\cline { 2 - 4 } & $\begin{array}{c}\text { Intercepto } \\
\text { Intercept }\end{array}$ & $\begin{array}{c}\text { Coeficiente de regressão }(\beta) \\
\text { Coefficient of regression }(\beta)\end{array}$ \\
\hline $\begin{array}{l}\text { Cálcio corporal/Ca na secção HH } \\
\text { Body calcium/Ca in HH section }\end{array}$ & 0,738271 & 0,460926 & $0,94^{* *}$ \\
$\begin{array}{l}\text { Fósforo corporal/P na secção HH } \\
\text { Body phosphorus/P in HH section }\end{array}$ & 0,335607 & 0,449298 & $0,93^{* *}$ \\
$\begin{array}{l}\text { Potássio corporal/K na secção HH } \\
\text { Body potassium/K in HH section }\end{array}$ & 0,050955 & 0,581673 & $0,88^{* *}$ \\
$\begin{array}{l}\text { Magnésio corporal/Mg na secção HH } \\
\text { Body magnesium/Mg in HH section }\end{array}$ & 0,014669 & 0,400000 & $0,49^{* *}$ \\
$\begin{array}{l}\text { Sódio corporal/Na na secção HH } \\
\text { Body sodium/Na in HH section }\end{array}$ & 0,069064 & 0,511287 & $0,70^{* *}$ \\
\hline
\end{tabular}

** Significativo $(P<0,01)$ (Significant $(P<.01)$.

comportamento semelhante das quatro raças para todas as características estudadas.

Verificou-se efeito linear $(\mathrm{P}<0,05)$ de regressão do peso corporal vazio (PCVZ), em função do peso vivo $(\mathrm{PV})$ dos animais $(\mathrm{PCVZ}=-31,3869+0,9324 * \mathrm{PV})$. $\mathrm{O}$ elevado valor do coeficiente de determinação $\left(r^{2}=0,95\right)$, na equação para predição do PCVZ a partir do PV, mostra bom ajustamento da equação aos dados.

O peso corporal vazio (PCVZ) de um animal com $400 \mathrm{~kg}$ de peso vivo $(341,6 \mathrm{~kg})$, estimado a partir da equação foi $2,46 \%$ inferior ao obtido com a equação específica para zebuínos desenvolvida por FONTES (1995), com base em 101 animais castrados e nãocastrados, e 1,02 e $0,79 \%$ superior ao obtido por FREITAS (1995) e CASTILLO ESTRADA (1996), respectivamente. O PCVZ estimado neste trabalho foi praticamente igual ao obtido pela equação de PAULINO (1996), que utilizou os mesmos animais do presente estudo, acrescidos daqueles pertencentes às categorias abate inicial $(\mathrm{AB})$ e mantença $(\mathrm{AR}), \mathrm{e}$ também coincide com aquele encontrado a partir da equação geral de FONTES (1995). Segundo este 
autor, o emprego desta equação poderá ser de grande utilidade, quando os animais experimentais são abatidos em abatedouros comerciais, onde torna-se impossível a determinação do peso corporal vazio.

\section{Conclusões}

Os teores de proteína, gordura, energia e macroelementos minerais da secção $\mathrm{HH}$, com exceção do magnésio, mostraram-se altamente correlacionados com a composição química corporal.

Tendo em vista os valores dos coeficientes de determinação apresentados, as equações baseadas na composição química da secção $\mathrm{HH}$ podem ser indicadas para estudos comparativos da composição corporal de zebuínos.

\section{Referências Bibliográficas}

AGRICULTURAL RESEARCH COUNCIL - ARC. 1980 The nutrient requirements of ruminants livestock. London: Commonwealth Agricultural Bureaux. 351p.

ALHASSAN, W.S., BUCHANAN-SMITH, J.G., USBORNE, W.R. et al. 1975. Predicting empty body composition of cattle from carcass weight and rib cut composition. Can. J. Anim. Sci., 55(3):369-376.

BERG. R.T., BUTTERFIELD, R.M. 1976. New concepts of cattle growth. New York: Sydney University. 240p.

BRAGA, J.M., DEFILIPO, B.V. 1979. Determinação espectrofotométrica de fósforo em extrato de solos e matéria vegetal. $R$. Ceres, 21(113):73-75.

CASTILLO ESTRADA, L. H. Composição corporal e exigências de proteína, energia e macroelementos minerais $(\mathrm{Ca}, \mathrm{P}$, $\mathrm{Mg}$, Na e K), características da carcaça e desempenho do nelore e mestiços em confinamento. Viçosa, MG: UFV, 1996. 129p. Tese (Doutorado em Zootecnia) - Universidade Federal de Viçosa, 1996.

COLE, J.W., RAMSEY, C.B., EPLEY, R.H. 1962. Simplefield method for predicting pounds of lean in beef carcass. J. Anim. Sci., 21(2):355.

FONTES, C.A.A. Composição corporal, exigências líquidas de nutrientes para ganho de peso e desempenho produtivo de animais zebuínos e mestiços europeu-zebu. Resultados experimentais. In: SIMPÓSIO INTERNACIONAL SOBRE EXIGÊNCIAS NUTRICIONAIS DE RUMINANTES, 1995, Viçosa, MG. Anais... Viçosa, 1995. p.419-455.
FOX, D.G. DOCKERTY, T.R., JHONSON, R.R. et al. 1976. Relationship of empty body weight to carcass weight in beef cattle. J. Anim. Sci., 43(3):566-568.

FREITAS, J.A. Composição corporal e exigência de energia e proteína de bovinos (zebuínos e mestiços) e bubalinos não castrados, em confinamento. Viçosa, MG: UFV, 1995. 132p. Tese (Mestrado em Zootecnia) - Universidade Federal de Viçosa, 1995.

HANKINS, O.G., HOWE, P.E. 1946. Estimation of the composition of beef carcasses and cuts. Washington, D.C. (Tech. Bulletin - USDA, 926).

HARVEY, W.R. 1987. Mixed model least squares and maximum likelihood computer program (LSMLWM). Versão PC - 1.

LANNA, D.P.D, BOIN, C., ALLEONI, G.F. et al. 1995. Estimativa da composição química corporal de tourinhos nelore através da gravidade específica. R. Soc. Bras. Zootec., 24(3):351-362.

MORAIS, C.A.C., FONTES, C.A.A., LANA, R.P. et al. 1993. Influência da monensina sobre a composição física e química da carcaça de bovinos castrados e não castrados. R. Soc. Bras. Zootec., 22(6):952-959.

NATIONAL RESEARCH COUNCIL - NRC. 1984. Nutrient requeriments of beef cattle. 6.ed. Washington, D.C. 90p.

NOUR, A.Y.M., THONNEY, M.L. 1994. Chemical composition of Angus and Holstein carcasses predicted from rib section composition. Technical note. J. Anim. Sci., 72(3):1239-1241.

PAULINO, M.F. Composição corporal e exigências de energia, proteína e macroelementos minerais ( $\mathrm{Ca}, \mathrm{P}, \mathrm{Mg}$, Na e $\mathrm{K}$ ) de bovinos não-castrados de quatro raças zebuínas em confinamento. Viçosa, MG: UFV, 1996. 80p. Tese (Doutorado em Zootecnia) - Universidade Federal de Viçosa, 1996.

PERON, A.J., FONTES, C.A.A., LANA, R.P. et al. 1993. Predição da composição corporal e da carcaça de bovinos através de métodos indiretos. R. Soc. Bras. Zootec., 22(2):238-247.

POWEL, W.E., HUFFMAN, D.L. 1968. An evaluation of quantitative estimates of beef carcass composition. J. Anim. Sci., 27(6):1554-1558.

SILVA, D. J. 1990. Análise de alimentos (métodos químicos e biológicos). Viçosa, MG: UFV. 165p.

WRIGHT, I.A., RUSSEL, J.F. 1984. The composition and energy content of empty body-weigth change in mature cattle. Anim. Prod., 39:365-69.

Recebido em: 12/11/99

Aceito em: 23/05/00 